"Relationship between talent management strategy efficiency with attracting, recruiting and developing human resources (case study: Iranian offshore oil company)"

$\begin{array}{ll}\text { ZUTHORS } & \text { Zahra Jafari } \\ \text { Mohamad Hamed Khanmohamadi }\end{array}$

Zahra Jafari and Mohamad Hamed Khanmohamadi (2016). Relationship between talent management strategy efficiency with attracting, recruiting and

ARTICLE INFO developing human resources (case study: Iranian offshore oil company). Problems and Perspectives in Management, 14(3-si), 388-395. doi:10.21511/ppm.14(3-si).2016.12

DOI http://dx.doi.org/10.21511/ppm.14(3-si).2016.12

RELEASED ON

Thursday, 15 September 2016

JOURNAL

"Problems and Perspectives in Management"

FOUNDER

LLC "Consulting Publishing Company "Business Perspectives"

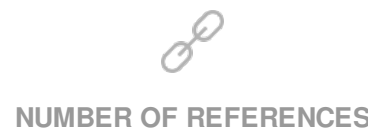

0
NUMBER OF FIGURES

0
NUMBER OF TABLES

0

C The author(s) 2023. This publication is an open access article. 
Zahra Jafari (Iran), Mohamad Hamed Khanmohamadi (Iran)

\title{
Relationship between talent management strategy efficiency with attracting, recruiting and developing human resources (case study: Iranian offshore oil company)
}

\begin{abstract}
Nowadays, competition between organizations has turned from developing tangible assets into developing intangible assets. Abilities and talents of its human resources and staffing is the most important element of intangible assets of any organization. Contribution to the actual potential of the current forces and special talent recruitment to fill gaps identified in can help organizations to achieve higher productivity in the area of talent management. The investigation aims to find the relationship between performance of talent management strategy with attracting, recruiting and human resources development in Iranian offshore oil company. The study population included $420 \mathrm{HR}$ headquarters in Tehran and the sample based on Cochrane Formula is 200 people. Three questionnaires were used to test hypotheses. Buckingham M. \& Vosburgh R. (2001) questionnaire was used to measure talent management; Beardwell I., L. Holden, T. Claydon. (2004) questionnaire was used to measure recruitment (2004) and finally Reuther, Robert (1996) was used to assess the individual development. The results revealed that there is a significant positive relationship between the ability and opportunity to hire human resources in Iranian offshore oil company. In addition, there is a significant positive relationship between the ability, opportunity and skills with the development of human resources.
\end{abstract}

Keywords: talent management, human resource development, human resource recruitment.

JEL Classification: M12, O13.

\section{Introduction}

Human resources management in a broad sense is a subset Management aimed at human resource management to achieve competitive advantage. The importance and role of human resource management was formerly known as personnel management, but it much has changed recently. In the early stages, the personnel management was seen as a tool for preservation, and human resources was seen as a factor of production. Human resources management, with primary emphasis on the human factor, came into existence with combining different scientific fields such as industrial relations and psychology. Human resource management in contemporary organizations is part of the success of an organization, in recent years gained strategic importance, and is seen as a key resource in organizational processes (Ferris et al., 2007. p. 118).

The foundation of any organization's wealth is of its employees in the form of knowledge, skills, and their motivations. Nowadays, it is important to have such a wealth, since, in the next decades and the next century, the main source of competitive advantage will not root in new technology, but the initiative, creativity, commitment and competence of labor (Jazini, 2006). It should be noted that the organization's most important asset is its human resources. In recent years, according to human resources in organizations, a large part of your time and money devoted to leading organizations.

(c) Zahra Jafari, Mohamad Hamed Khanmohamadi, 2016.

Zahra Jafari, Department of Accounting, Damavand Branch, Islamic Azad University, Damavand, Iran.

Mohamad Hamed Khanmohamadi, Assistant Professor, Faculty members of Islamic Azad University, Damavand, Iran.
The success or failure of an organization depends on how it is to attract and retain human resources (Jazini, 2000).

Selection and use of the most qualified people in each occupation is one of the most important issues and decisions considered by management (Mohammadi et al., 2004. pp. 135-156). On the other hand, training and human resource development have stated as the organizational planning effort to facilitate learning and acquiring job-related competencies (Neo, 2008, pp 4-49). Training and staff development links with not only the acquisition of knowledge and skills and building capacity, but also the power of entrepreneurship, familiarizing employees with the most important organizational changes, activities and decisions (Vemic, 2007, pp. 209-216).

It should be noted that, today, organizations are looking to develop a practical model for talent management. Opening the continued growth of the organization and its activities means increasing the number of high and middle level managers and to fill such positions, the organization needs to identify potential talent within the organization and in the absence of such talents attract the right people from outside the organization. Therefore, there are programs to identify needs and human resources training to develop and deploy their anticipated time in particular organizational level can be part of the functions of talent management in the organization. Therefore, as explained in this study, we are to examine the relationship between performance of talent management strategy with attracting, recruiting and human resources development in Iranian offshore oil company. 


\section{Theoretical foundations}

1.1. Talent management. The consulting group McKinsey in a report called "war for talent" (Michael et al., 2001) initially used the term talent management. The report emphasizes that the talent management is essential for organizational success, because provides access to competitive advantage through the identification, development and reorder capable staff. From this time onwards talent management are considerable for researchers, managers and practitioners of organization and management. It seems that this situation has occurred in situations that the challenges of human capital maximization of the benefits of an organization have much more important in economic slowdown. According to researchers, talent management issues have been proposed in order to give effect to human resource management to gain competitive advantage and its potential to create added-value. Talent management challenges the emphasis of bureaucratic systems and structures and undermines human resources egalitarian models. Indeed, a monopoly of talent management approach and a differentiated/segmented view provides human resources in which a special talent agencies more than others given the price (Powell et al., 2010, pp. 179-189).

In this regard, some organization managers have acknowledged that the head of talent management in human resources is key topics (Sandler, 2006, pp. 1-3).

1.2. Human resources strategies. Training and human resource development has been stated as organizational planning effort to facilitate learning and the acquisition of job-related competencies (Neo, 2008, pp. 4-49). Training and staff development links with not only the acquisition of knowledge and skills and building capacity, but also the power of entrepreneurship, familiarizing employees with the most important organizational changes, activities and decisions (Vemic, 2007, pp. 209-216). With the emergence and persistence of ideas and knowledge management system, today, along with education and human resource development, organizations can use knowledge management capabilities, particularly, knowledgesharing process not only to improve the level of information, knowledge, skills and experience of staff, but also to increase competitiveness, and achieve organizational goals and benefit. In other words, two important scientific fields of training and development and knowledge management work by focusing on human capital capacity conservation and development in organizations, since education and human resource development are mentioned as a strategy and tools for knowledge sharing process (Jung, 2010).

\section{Research background}

Giovanni et al. (2016) have designed a model to measure the effectiveness of their employment at the University. According to experts, they proposed an effective way to recruit professors at the University based on their research functions. The result of this study showed that assessing the specialty and research resume of the teachers have important role in recruiting them. Also stated, job parameters can be important to monitor false factors such as nepotism and relationships behind the scenes to prevent the hiring incompetent. Steinert, Y. Mann, K. Centeno, A. Dolmans, D. Spencer, J. Gelula, M. \& Prideaux, D. (2016) in a study entitled "Human resources and personal development" based on the systematic approach have noted that which attracted more programs and faculty development include seminars, workshops, short courses, and long-term programs. The characteristics of effective faculty development program is having a high priority for experiential learning, providing feedback, having good cooperation relationships with colleagues, extremely good interventions designed according to the principles of adult learning theory, and methods of effective teaching and learning.

Wootton, D. \& Kenneth Stone, B. (2015) in a study entitled "New methods of learning, human resource development", express: the study aims to answer this question: How can I teach professional skills when making decisions in the context of the increasing role of knowledge in an interactive virtual learning environment used for human resource empowerment and development? The research has studied a group of part-time students who, using virtual learning environment, pursued professional development programs. The results show that using advanced technology and communication technology and flexible teaching methods due to the economic crisis and economic situation is effective in human learning resource development. Finally, the use of flexible and patchwork virtual learning environment creates a set of management opportunities to promote HRD with the development of technical and moral skills.

\section{Research methodology}

The research method used is a descriptive approach of the survey methodology. So that it aims to describe the conditions of phenomena studied and provide recommendations based on the findings of the research. On the other hand, the study was based on objective is practical and is based on the nature and methods is of correlations. We, according to the type of research, used correlation coefficient to investigate their correlation with each other. 
3.1. Hypotheses. The first main hypothesis: talent management and HR recruitment in Iranian offshore oil company has a significant relationship.

\subsubsection{Sub-hypotheses:}

1. There is a significant relationship between ability and recruiting human resources in Iranian offshore oil company.

2. There is a significant relationship between skill and recruiting human resources in Iranian offshore oil company.

3. There is a significant relationship between opportunity and recruiting human resources in Iranian offshore oil company.

The second major hypothesis: there is a significant relationship between talent management and human resources development in Iranian offshore oil company.

3.2. Hypotheses. There is a significant relationship between ability and development of human resources in Iranian offshore oil company.

1. There is a significant relationship between skills and development of human resources in Iranian offshore oil company.

2. There is a significant relationship between opportunity and development of human resources in Iranian offshore oil company.

\subsection{Variables. 3.3.1. Independent variable.}

1. Talent is a natural ability having a chance to emerge. Implementation of this innate ability, at the right moment, needs effort and the so-called, skill acquisition in that particular field. For crystallization talent, indeed, the three elements of innate ability, opportunity and skills exist side by side. In particular, the separation of talent could be the basis for planning the organization of executives and professionals provide in the field of talent management (Buckingham et al., 2001. p. 18).

Innate ability: As mentioned in the definition of talent, talent more than anything is innate ability within a specific context. Unlike skills that can be learned, the ability of the person rises and, therefore, is unique. There is an innate ability in person, a necessary condition for the development of talent. The ability inherent in the concept of talent is central to the issue. There are other two pillars in terms of talent that should be considered; two pillars are the opportunity of utilizing the talents and skills of talent. These two conditions are considered large enough to cause potential.

Opportunity: To emerge, talent needs opportunities. Talents may be latent; this means that a person may be enjoyed from a special capability but does not have any opportunity to develop the ability. This clearly shows to managers that to take advantage of the talent, it is necessary to provide opportunities for staff development of talent. Providing these conditions can encompass a range of activities and actions of management. Here is something that should be remembered is that never talent in itself is limited to a particular class, race and gender and the society, however, the opportunity to express talents may be very limited.

Skills: The last element of talent is proficiency in the use of talent. Skill is ability to work efficiently that is result of learning or training. This means that incidence of talent, it must be taught how capacity utilization; that results from repetition and effort. Talent puzzle is completed with these three elements together: inherent ability, opportunity and skill.

\subsubsection{Dependent variable.}

1. Employment is a contract between the employee and the employer, which could include oral and written guarantee to provide services and monitoring, which is signed between the parties.

The contract usually guaranteed a profit from the workers to the employer associated with wage. Contract is a necessary mutual agreement in order to create a legal effect. In simple terms, contract realized if creation of a legal effect including sale, lease and so on requires two to intersect and consent. Beardwell et al. (2004) point out that the recruitment and selection processes focused on the identification and immunization the right people to face the human resources needs of an organization. The term "employment ended" and "selection began", most consistently, are used as a topic. However, in order to analyze, it is better to separate the two, however, employment is the first half of our definitions and selection is the second half. Recruitment refers to identification and hiring volunteers, and the selection is focused on selecting the most appropriate. Selection represents the final step of decision-making in the hiring process (Cawling and Mylar, 1990).

In the study, we have used Beardwell and Wright (2004) questionnaire, which includes subscales as follows:

- Individual fit with the job. Actually, this refers to the characteristics of individual components in terms of mental and physical capabilities and skills needed according to the job description and job specification.

- Academic studies. Another component of HR is having a college education for employment in organizations. Accordingly, education plays an important role for employment by categories of positions from simple to hard, as well as skillbased features. 
- Work experience. According to this model, the last component of $\mathrm{HR}$ is an experienced and professional experiences, which can show a person more capable than others.

2. Individual development is to provide more freedom, independence, accountability for decision-making and self-controlling in doing things for employees (Mullins, 1999, p. 625). Conger and Kanungo (1998) argued that development is a process making improve feeling of "self-efficiency" among the staff. In this process, conditions are recognized that foster empowerment and gain productive information using organizational operations and informal techniques (Ivancevich et al., 2005, p. 394). In this study, the Krether (1996) model is used in order to assess individual development of human resources in the organization, which includes the following components:

- Mental ability. Intelligence and mental ability is what a person needs for intellectual work. Type of job determines a person's intelligence abilities. Generally, the higher level an employee placed in the administrative hierarchy, higher verbal ability and intelligence should have so that $\mathrm{s} / \mathrm{he}$ can do the job successfully (Robbins, 1378, p. 130). Therefore, attention (and trust) to mental abilities and talents of people and creating an environment conducive to the development is the development of staff and will help organizations to solve their problems.

- Physical ability. Physical ability is fitness between a person's physical and physical capacity with tasks associated with each job including physical strength, height, weight, bowel health, vision, smell and hearing and so on (Mir Sepasi, 2002, p. 113).

- Knowledge. Knowledge is made of three elements: data, information and knowledge. Data is a set of facts about a phenomenon. Information includes organizing, categorizing and classifying data in meaningful patterns and finally, knowledge is information combined with experience, reflection the composition and makes possible the correct action (Davenport and Prusak, 1998). Knowledge is a flexible and convertible combination of experience, values, meaningful information and insights for professionals that offer a framework to evaluate and enhance the information and new experiences. Knowledgebased employees play an important role in generating value for organizations. These forces are trying to solve their mental challenges and expand their technical knowledge. Developing human resources assess the activities carried out closely and tries to devote their knowledge and skills at the best in the organization (Attafar and Shari'atmanner, 2007).
- Skills. Skills include all of the basic necessary capabilities, which make practical work in the conditions specified (Mirsepassi, 2002, p. 113). Mainly there are three areas of expertise including technical skills, human skills and conceptual skills intended for managers and employees. The ability to apply knowledge, methods and tools necessary to perform certain tasks acquired through experience, education and training is called technical skills, which is often seen in skilled employees and operational managers (Rezaeian, 2003).

- Inspiration. Having the motivation to work and direct the healthy motives is necessity in use of human resources (Mir Sepasi, 2009, p. 366). Motivation, from the perspective of human resource management, is to motivate staff to work and pushing them to function in a satisfactory job (Mirsepassi, 2002, p. 358). Some experts define a responsible of individual development for intrinsic motivation as development, empowerment of the individual, the authority and capacity (Abtahi and 'Aby, 2007). Regarding to the needs and motivations of employees and rewarding is emphasized based on the performance and spiritual rewards (immaterial) are more important than material rewards (Molhem, 2004, pp. 72-93). Persuasive subsystems cannot be effective and efficient in order to promote individual rate. In this context, it is better to all of the management incentive system including payments, rewards, incentives and punishments, all be used in a single integrated device and in conjunction with each other to realize a positive synergy (Foundation for Human Resources Empowerment of Iran, 2008, p. 107).

\section{Experimental results}

\subsection{Descriptive statistics.}

Table 1. Descriptive statistics

\begin{tabular}{|l|c|c|c|c|}
\hline & Average & $\begin{array}{l}\text { Standard } \\
\text { deviation }\end{array}$ & Minimum & Maximum \\
\hline Talent management & \multicolumn{5}{|l|}{} \\
\hline Inherent abilities & 3.394 & 0.773 & 1 & 5 \\
\hline Opportunities & 3.984 & 0.886 & 1 & 5 \\
\hline Skills & 3.638 & 0.614 & 1 & 5 \\
\hline Recruitment & 3.394 & 0.773 & 1 & 5 \\
\hline $\begin{array}{l}\text { Individual fit with a } \\
\text { career }\end{array}$ & 3.701 & 0.578 & 1 & 5 \\
\hline Academic & 3.681 & 0.627 & 1 & 5 \\
\hline Experience working & & & \\
\hline Human resource development & 2.571 & 0.691 & 1 & 5 \\
\hline Mental abilities & 2.654 & 0.703 & 1 & 5 \\
\hline Physical abilities & 2.761 & 0.661 & 1 & 5 \\
\hline Knowledge & 3.233 & 0.660 & 1 & 5 \\
\hline Skills & 3.527 & 0.782 & 1 & 5 \\
\hline Motivation & & & \\
\hline
\end{tabular}


Mean components of the independent variables showed that components of talent management opportunities as a subscale with an average of 3.984 and components of mental ability as one of the subscales of the development of human resources with an average of $2.571 \mathrm{had}$ the highest and the lowest scores, respectively.

This means that there are more opportunities in Iranian offshore oil company so that employees feel can demonstrate their capabilities and they can have the opportunity to improve in their jobs and positions. On the other hand, the mental abilities as a component of human resources development have the lowest rate that could be a manifest that people are convinced that mental abilities do not play an important role in individual development.

4.1.1. Test data distribution. As Table 2 shows, significance level of $Z$ for all variables in error level of $5 \%$ is significantly smaller than $5 \%(0 / 05>\mathrm{Sig})$. Hence, with a $95 \%$ confidence, $H_{0}$ assumption of normal distribution of data is rejected and $\mathrm{H} 1$ assumption was accepted. In other words, it was revealed that the research data are not normal and nonparametric test has to be applied to test hypotheses. Thus, according to the results in the rest of research, nonparametric methods were used to test the hypothesis and comparing demographic groups.

Table 2 . Normality test results for variables

\begin{tabular}{|l|c|c|c|c|c|}
\hline \multicolumn{1}{|c|}{ Variable } & $\begin{array}{c}\text { Absolute } \\
\text { value }\end{array}$ & Positive & Negative & $\begin{array}{c}\text { Z- } \\
\text { statistic }\end{array}$ & $\begin{array}{c}\text { Significant } \\
\text { level }\end{array}$ \\
\hline $\begin{array}{l}\text { Inherent } \\
\text { capabilities }\end{array}$ & 0.124 & 0.124 & -0.121 & 2.003 & 0.001 \\
\hline Opportunities & 0.170 & 0.170 & -0.122 & 2.748 & 0.000 \\
\hline Skills & 0.148 & 0.148 & -0.095 & 2.393 & 0.000 \\
\hline $\begin{array}{l}\text { Individual fit with } \\
\text { the job }\end{array}$ & 0.125 & 0.125 & -0.097 & 2.020 & 0.001 \\
\hline Academic & 0.094 & 0.090 & -0.094 & 1.516 & 0.020 \\
\hline Work experience & 0.210 & 0.094 & -0.210 & 3.406 & 0.000 \\
\hline Mental ability & 0.142 & 0.142 & -0.115 & 2.304 & 0.000 \\
\hline Physical ability & 0.149 & 0.149 & -0.149 & 2.418 & 0.000 \\
\hline Knowledge & 0.104 & 0.104 & -0.101 & 2.007 & 0.000 \\
\hline Skills & 0.132 & 0.132 & -0.128 & 2.654 & 0.004 \\
\hline Motivation & 0.127 & 0.127 & -0.123 & 2.615 & 0.003 \\
\hline
\end{tabular}

4.2. Statistical analysis of assumptions. The first main hypothesis: there is a significant relationship between talent management and HR in Iranian offshore oil company.

\subsubsection{Hypotheses:}

1. There is a significant relationship between the ability and employing human resources in Iranian offshore oil company.

Table 3. Spearman correlation coefficient test

\begin{tabular}{|l|c|c|}
\hline \multirow{2}{*}{ Innate ability and hire } & Significance level & Correlation coefficient \\
\cline { 2 - 3 } & 0.607 & $0 / 000$ \\
\hline
\end{tabular}

As shown in Table 3, the achieved significant level is 0.000 that is less than $\alpha=0 / 05$. Therefore, the relationship between innate ability to hire people is accepted and this test is significant. The correlation coefficient between the innate ability to hire is 0.607 , which represents a direct and positive relationship between the variables, as well as great is the strength of this relationship.

2. There is a significant relationship between skill and employing human resources in Iranian offshore oil company.

Table 4. Spearman correlation coefficient test

\begin{tabular}{|l|c|c|}
\hline \multirow{2}{*}{ Individual skill and hiring } & Correlation coefficient & Significant level \\
\cline { 2 - 3 } & 0.612 & $0 / 104$ \\
\hline
\end{tabular}

As shown in Table (4), the significant level is 0.104 that is more than $\alpha=0 / 05$. Therefore, the relationship between individual skills by hiring human resources Iranian offshore oil company was not confirmed.

3. There is a significant relationship between the opportunity and employing human resources in Iranian offshore oil company.

Table 5. Spearman correlation coefficient test

\begin{tabular}{|l|c|c|}
\hline \multirow{2}{*}{ Employment and opportunities } & Correlation coefficient & Significant level \\
\cline { 2 - 3 } & 0.584 & 0.002 \\
\hline
\end{tabular}

As shown in Table (5), the significant level is 0.000 that is less than $\alpha=0 / 05$. Therefore, the relationship between employment and opportunities is accepted and this test is significant.

In other words, opportunities with a correlation coefficient (0.584) and a significant positive correlation with employment.

The second main hypothesis: there is a significant relationship between talent management and human resources development in Iranian offshore oil company.

\subsubsection{Hypotheses:}

1. There is a significant relationship between ability and developing human resources in Iranian offshore oil company.

Table 6. Spearman correlation coefficient test

\begin{tabular}{|l|c|c|}
\hline $\begin{array}{l}\text { Innate ability with human } \\
\text { resources development }\end{array}$ & Correlation coefficient & Significant level \\
\cline { 2 - 3 } & 0.598 & $0 / 000$ \\
\hline
\end{tabular}

As it can be seen in Table 6, the significant level is 0.000 that is less than $\alpha=0 / 05$. Therefore, the relationship between the innate ability and the human resources development is accepted and this test is significant.

The correlation coefficient between the innate ability of individuals to the development of human resources 
is 0.598 , which represents a direct and positive relationship between the variables, as well as the strength of this relationship is great.

2. There is a significant relationship between skills and development of human resources in Iranian offshore oil company.

Table 7. Spearman correlation coefficient test

\begin{tabular}{|l|c|c|}
\hline \multirow{2}{*}{$\begin{array}{l}\text { Skills development and human } \\
\text { resources }\end{array}$} & Correlation coefficien & Significant level \\
\cline { 2 - 3 } & 0.619 & $0 / 000$ \\
\hline
\end{tabular}

As shown in Table (3), the significant level is 0.000 that is less than $\alpha=0 / 05$. Therefore, the relationship between the developments of human resource skills is accepted and this test is significant.

The correlation coefficient between the developments of human resource skills is 0.607 , which represents a direct and positive relationship between the variables, as well the strength of this relationship is great.

3. There is a significant relationship between the opportunity and the development of human resources in Iranian offshore oil company.

Table 8. Spearman correlation coefficient test

\begin{tabular}{|l|c|c|}
\hline Human resource and & Correlation coefficient & Significant levels \\
\cline { 2 - 3 } development opportunities & 0.522 & 0.002 \\
\hline
\end{tabular}

As shown in Table 8, significant level is 0.000 that is less than $\alpha=0 / 05$. Therefore, the relationship between the development of human resources and opportunities is accepted and this test is significant. In the other words, opportunity has a correlation coefficient $(0.522)$ and a significant positive correlation with the development of human resources.

\section{Conclusion}

Experts in the field of human resources in the 21st century consider success of the organization in the effective use of talented people and believe that the only competitive advantage of each other's organizations is having educated and valued employees and their efficiency of the staff is the biggest challenge of the third millennium managers. Organizations that are looking for their survival or looking to develop, needs to attract, nurture and maintain talented staff. It is notable that changes in the present era are considered as an essential factor for future development. Elite can be extremely valuable to organizations and brought growth and prosperity of their organizations. However, few organizations focused on human investment and most of them based themselves on new technologies, planning systems and their software investment executive. Whereas, modern organizations consider their progress depends on investment in human resources and are trying to guide their human resource's talent to the ultimate success.
According to the description given, a summary of the results is as follows.

The first main hypothesis: talent management and HR Iranian offshore oil company have a significant relationship.

$1^{\text {st }}$ hypothesis. The ability and employing human resources in Iranian offshore oil company have a significant relationship.

In analyzing the results of this hypothesis, it was revealed that people with individual capabilities and expertise have more and better employment chances in the firm, because people who do not have the ability to run jobs and duties put the company into trouble and that the company cannot move forward as it was planned and pre-determined. Another point from the individual psychological view is that if a person positions an individual job role that does not have the necessary ability and capacity, certainly, s/he would face with problems of industrial psychology such as burnout and job dissatisfaction and it is troublesome for the individual.

The result of this research corresponds to Hudson (1995) in terms of the concept, which states human capital should be chosen based on their capabilities and training.

$2^{\text {nd }}$ hypothesis. There is a significant relationship between the skills and human resources hiring in Iranian offshore oil company.

In analyzing this result, it was found that participants in this study believed that the skills could not have a decisive role in hiring. This means that the company has not considered the role of individual skills before hiring and perhaps the relationships behind the scenes and lack of attention to meritocracy can be effective in this process.

Result of this hypothesis is consisted with Hazlina \& Zubaidah (2008).

$3^{\text {rd }}$ hypothesis. There is a significant relationship between opportunity and hiring human resources in Iranian offshore oil company.

In analyzing the results, this hypothesis should be expressed that creating opportunities for growth and demonstrate the ability of individual can have an important role in hiring. The result revealed that the more people have more opportunity to present themselves and their capabilities they can be an important and decisive role in their recruitment. This can be very effective for organizations, because they can attract more people having more and better features and this, in the future, will play a very important role for companies. 
Results of this hypothesis are consistent with Cuganesan (2006).

2ns major hypothesis: Talent management and human resources development in Iranian offshore oil company have a significant relationship.

$1^{\text {st }}$ hypothesis. There is a significant relationship between ability and developing human resources in Iranian offshore oil company. Analyzing this hypothesis, it was found that by increasing the innate ability of people, both intellectually and physically, as well in terms of communication capabilities, could have an important and significant role in the development of human resources in development and promotion of responsibilities and positions. It should be noted that people always grow in a company posts with perseverance and effort along with individual empowerment and selfesteem, otherwise, not possible.

Result of this hypothesis is consistent with Farooqi and Hussain Poor (2005).

$2^{\text {nd }}$ hypothesis. There is a significant relationship between the skills and the human resources development in Iranian offshore oil company.

This hypothesis should be expressed that with the increasing amount of individual skills in line with the duties and positions, it can be expected that individual work be done more accurate and commitment. Since, the employee is not interested his skills and capabilities that perhaps are results of years of effort and hard work and experience, easily destroy with intentional and unintentional oversight; under these circumstances, other people in the organization realize that he is competent for occupational and organizational development and better conditions will be provided for him.

Results of this hypothesis are consistent with Farooqi and Hussain Poor (2005).

$3^{\text {rd }}$ hypothesis. There is a significant relationship between opportunity and development of human resources in Iranian offshore oil company.

It, in analyzing the results of this hypothesis, should be said that providing opportunity to demonstrate the ability, and the ability of individuals in Iranian offshore oil company has caused to expect that the development of human resources happens better and more positive. In the other words, companies should structure their programs so to provide the conditions necessary for the growth and improvement of people in post and specify the scope of work. This means that we can see the development of more efficient human resources and organization will benefit from the result when offer the proper chance to people and improve their capabilities.

The result of this research corresponds to Hudson (1995) in terms of the concept, which states trained human capital should train and elect and develop be based on their ability.

\section{References}

1. Attafar, Ali, Shariatmanesh, Mehdi. (2007). Key characteristics of human resources and their role in value creation for the organization, the Eighth International Conference of Quality Managers, Tehran.

2. Beardwell, I., Holden, L., Claydon, T. (2004). Human Resource Management. Harlow: FT/Prentice Hall.

3. Buckingham, M. \& Vosburgh, R. (2001). The 21 st century human resources function: It's the talent, stupid! Human Resource Planning, 24 (4), pp. 17-23.

4. Conger Jay, A. \& Rabindra, N. Kanungo. (1988). The empowerment process: Integrating Theory \& Practice, Academy of Management Review, 13 (3).

5. Cowling, A., Mailer, C. (1990). Managing Human Resources, 2nd Edition. London: Edward Arnold.

6. Davenport, T.H. and Prusak, L. (1988). Working knowledge, how organizations manage what they know. Boston: Harvard Business School Press.

7. Foroughi, Leila, Hosseinpour, Davoud. (2005). The role of intellectual capital and human resources development strategy performance, The Journal of Human Resources Management of University of Imam Hussein (AS), 2, pp. 133-149.

8. Foundation of empowering Human Resources in Iran. (2008). Empowering human resources. Andishehgostar press.

9. Giovanni, Abramoa, Ciriaco, Andrea D’Angelob, Francesco, Rosat. (2016). A methodology to measure the effectiveness of academic recruitment and turnover, Journal of Informatics, 10 (1), February, pp. 31-42.

10. Hazlina, H. and Zubaidah, Z.A. (2008), Relationship between intellectual capital and firms' performance: evidence from public listed companies in Malaysia. Proceedings of International Accounting Business Conference, Johor Bahru, Malaysia.

11. Ivancevich, J., Konopaske, R. and Matteson, M. (2005). Organizational behavior and management. NewYork: McGraw-Hill.

12. Kritner, Robert. (1996). Organization Behavior, then Englwood cliffs. New Jersey: Prentice-hall.

13. Melhem, Y. (2004). The antecedents of customer contact employees' empowerment, Employee Relation, 26 (1).

14. Michaels, E. \& Handfield-Jones, H. \& Beth, A. (2001). The war for talent. McKinsey \& Company Inc.

15. Mirsepassi, Nasser. (1384). Strategic human resource management and labor relations. Mir press.

16. Noe, R.A. (2008). Employee training \& Development. Fourth edition. McGraw Hill. pp. 4-49. 
17. Paul Iles, Xin Chuai \& David Preece. (2010). Talent Management and HRM in Multinational companies in Beijing: Definitions, differences and drivers, Journal of World Business, 45, pp. 179-189.

18. Rezaeian, Ali. (2003). Principles of organization and management, $5^{\text {th }}$ edition, Samt press.

19. Robbins, Stephen. (2008). Organizational behavior, 1, the Cultural Research Bureau.

20. Sandler, S. (2006). Critical issues in HR drive, priorities: is talent management, HR Focus, 83 (1), pp. 1-3.

21. Steinert, Y., Mann, K., Centeno, A., Dolmans, D., Spencer, J., Gelula, M. \& Prideaux, D. (2016). A systematic review of faculty development initiatives designed to improve teaching effectiveness in medical education, $B E M E$ Guide Medical Teaching, 28 (6), pp. 497-526.

22. Suresh, Cuganesan. (2006). Reporting organizational performance in managing human resources: Intellectual capital or stakeholder perspectives? Journal of Human Resource Costing \& Accounting, 10 (3), pp. 164-188.

23. Vemic, J. (2007). Employ Training and Development and the Learning Organization, Economics and Organization, 4 (2), pp. 209-216.

24. Wootton, D. \& Kenneth Stone, B. (2010). Modern learning methods for HRD, The clinical legal education (CLE) approach, Journal of European Industrial Training, 34 (8-9), pp. 839-851.

25. Young, R. (2010). Knowledge Management Tools \& Techniques Manual. APO, P5. 